\title{
Endogenous estrogen exposure in relation to distribution of histological type and estrogen receptors in gastric adenocarcinoma
}

\author{
Evangelos Chandanos ${ }^{1}$, Carlos A. Rubio ${ }^{2}$, Mats Lindblad ${ }^{1}$, Chongqi Jia ${ }^{3}$, Apostolos V. Tsolakis ${ }^{4}$, \\ Margaret WARNER $^{5}$, JAN-Åke GuSTAFSSON ${ }^{5}$, and JESPER LAGERGREN ${ }^{1}$ \\ ${ }^{1}$ Unit of Esophageal and Gastric Research (ESOGAR), Section of Surgery, Department of Molecular Medicine and Surgery, Karolinska \\ Institutet, Stockholm, Sweden \\ ${ }^{2}$ Department of Pathology, Karolinska University Hospital, Stockholm, Sweden \\ ${ }^{3}$ Department of Epidemiology and Health Statistics, Shandong University, Shandong, P.R. China \\ ${ }^{4}$ Department of Medical Sciences, Section of Endocrine Oncology, University Hospital, Uppsala, Sweden \\ ${ }^{5}$ Division of Medical Nutrition, Department of Biosciences and Nutrition, Karolinska Institutet, Novum, Huddinge, Sweden
}

\begin{abstract}
Background. Estrogen might protect women against gastric adenocarcinoma of the intestinal histological type. We addressed this hypothesis and proposed that gastric estrogen receptors (ERs) are involved.

Methods. A population-based cohort of patients with gastric adenocarcinoma diagnosed in 1958-2004 in the county of Stockholm was identified through the Swedish Cancer Register. The patients were categorized regarding their endogenous estrogen exposure at diagnosis into: women aged less than 50 years, labelled "exposed women" $(n=364)$, men aged less than 50 years, labelled "unexposed men" $(n=396)$, and women aged more than 70 years, labelled "unexposed women" $(n=3008)$. Tumor specimens were reviewed, and 289 cases were classified into intestinal $(n=101)$ or diffuse type $(n=$ 188). Cases of intestinal adenocarcinomas $(n=45)$ were tested for presence of ERalpha, ERbeta, and ERbeta cx by immunohistochemistry.

Results. Compared to "exposed women", the intestinal type of gastric adenocarcinoma was more than four times more common among "unexposed men" (odds ratio [OR], 4.7; 95\% confidence interval [CI], 2.2-10.3) and nine times more common among "unexposed women" (OR, 9.1; 95\% CI, 4.319.6). No differences in ER expression were found. A comparison of ERs in tissues taken from the tumors and adjacent gastric mucosa revealed a loss of ERbeta and a gain of ERalpha in the tumor cells. The presence of ERbeta cx was identified for the first time in gastric tumors.

Conclusion. Gastric adenocarcinoma of the intestinal type is less common in women with high endogenous estrogen exposure, indicating a preventive effect of estrogen. No differences in the distribution of ERs was found between the three estrogen exposure groups. The presence of ERbeta cx in gastric cancer warrants further investigation.
\end{abstract}

Offprint requests to: E. Chandanos

Department of Surgery, P9:03, Karolinska University Hospital, SE-171 76 Stockholm, Sweden

Received: December 10, 2007 / Accepted: May 20, 2008
Key words Stomach · Neoplasm - Sex hormone - Intestinal · $\beta c x$

\section{Introduction}

Gastric adenocarcinoma is the fourth most common cancer worldwide [1], but the male predominance in the incidence of this tumor remains unexplained. For every female patient, two to three males are affected [1]. It has been proposed that estrogen might protect women against this cancer [2], a hypothesis supported by some epidemiological studies [2-6]. A reported 10- to 15-year delay in the onset of gastric adenocarcinoma, exclusively of the intestinal type in females, suggests a protective effect of endogenous estrogen [2]. If estrogen prevents the occurrence of the intestinal type of gastric adenocarcinoma, a biological mechanism needs to be established. The effects of estrogen on the cell are typically mediated by estrogen receptors (ERs). Two types of ERs have been identified;ERalpha $(\alpha)$ [7] and ERbeta $(\beta)$ [8], and both have been observed in gastric $[9,10]$ as well as other tissue. Moreover, a splicing variant of ER $\beta$ has recently been discovered, i.e., ER $\beta c x$ [11], but the possible occurrence of this receptor has not previously been studied in gastric tumors. We hypothesized that high current endogenous estrogen exposure decreases the isolated risk of developing the intestinal type of gastric adenocarcinoma, and not the diffuse type, and that this effect is mediated by the action of estrogen on gastric ERs. To address these hypotheses, we studied samples of gastric adenocarcinoma tissues from patients in a population-based cohort with high and low endogenous estrogen exposure, and compared the distribution of the intestinal and diffuse histological type and ERs $\alpha, \beta$, and $\beta c x$ in randomly selected intestinal tumors. 


\section{Patients, mate rials, and methods}

\section{Study design}

This was a population-based cohort study of patients with gastric adenocarcinoma, diagnosed in the county of Stockholm during the period 1958 to 2004 inclusive. The patients were identified in the Swedish Cancer Register and categorized into three groups with regard to their endogenous estrogen exposure at the time of the diagnosis: (1) females younger than 50 years of age, i.e., before the menopause, representing the group of "exposed women"; (2) males younger than 50 years, representing the group of "unexposed men"; and (3) females over the age of 70 years, i.e., at least 20 years after the menopause, representing the group of "unexposed women". Histopathological evaluation was conducted to verify the diagnosis of gastric adenocarcinoma and to further classify the adenocarcinomas into the intestinal or diffuse type. Finally, in randomly selected cases of intestinal adenocarcinoma, the occurrence of ERs $\alpha, \beta$, and $\beta \mathrm{cx}$ was determined, using immunohistochemistry.

\section{Identification of study participants}

All clinicians and pathologists in Sweden are obliged to report all newly diagnosed cancer cases to the Swedish Cancer Register. This Register has been shown to have a completeness rate of $98 \%$ for gastric cancer [12]. For the registration of cancer diagnoses, the Register has used the seventh revision of the International Classification of Diseases (ICD) (WHO/HS/CANC/24.1 Code for anatomical location) between 1958-1986. For the years 1987-1992, the ICD-9 coding system has been followed (WHO ninth revision 1976); for the period 1993-2004, the ICD-O-2/ICD-10 (ICD for Oncology, second edition; WHO Geneva 1990) has been used; and since 2005, the ICD-O/3 (third edition; WHO Geneva 2000) has been used. The Swedish Cancer Register translates the different classifications to ICD-7 in order to be able to follow the incidence of various cancer forms.

The following ICD codes were used to identify the gastric cancer cases in the Register: 151 (ICD-7); 151.09 (ICD-9), and C16.0-9 (ICD-10). After restriction of the Register to the county of Stockholm, 364 patients with gastric cancer were identified in the "exposed women" group, 396 patients in the group of "unexposed men", and 3008 patients in the group of "unexposed women".

\section{Determination of the type of gastric adenocarcinoma- intestinal or diffuse}

We selected the latest consecutive 150 cases in each group as eligible for further evaluation. Among these
450 cases, we requested histological sections from biopsies and surgical specimens of the 416 cases filed at the six major pathology departments in the county of Stockholm. Of these, we retrieved histological material from 356 cases (86\%). Two investigators (E. C. and C. A. R.), blinded to the group categorization (age and sex) of the patients, reviewed all specimens. They verified or refuted the gastric adenocarcinoma diagnosis and categorized each adenocarcinoma histologically into the intestinal or diffuse type in accordance with the Laurén classification [13]. Specimens of mixed histological types were classified according to Ming as being of the diffuse type [14]. The 289 patients $(81 \%)$ with a verified gastric adenocarcinoma and sufficient histological material for evaluation were included for final analysis. Of these, 101 (35\%) had the intestinal type of gastric adenocarcinoma.

\section{Evaluation of estrogen receptors}

Among the 101 cases of intestinal gastric adenocarcinoma that were evaluated histopathologically, 45 cases were randomly selected for immunohistochemical analysis of the ERs $\alpha, \beta$, and $\beta \mathrm{cx}$. Because the specimens from the selected tumors were mainly endoscopic biopsy samples, only a limited amount of tissue was available for immunohistochemistry in some cases. Consecutive sections, each $4-\mu \mathrm{m}$-thick, were cut from paraffinembedded material. One investigator (E. C.) performed the immunohistochemistry according to a previously described protocol [15]. In brief, we used the following antibodies and dilutions: rabbit anti ER $\alpha$ from Santa Cruz Biotechnology (Santa Cruz, CA, USA; 1: 120), and chicken polyclonal antibody anti-ER $\beta 503 \mathrm{IgY}$ (1: 200) and anti ER $\beta c x$ sheep anticlonal antibody (1: 200; both produced at our laboratory).

ER $\beta$ antibody was raised against human ER $\beta$ protein without the $\mathrm{N}$-terminal amino acids. It was raised in hens and the $\operatorname{IgY}$ was purified from egg yolks. This antibody has been extensively used in many laboratories throughout the world. The cx antibody was raised in sheep against the cx peptide; this antibody has also been used in many laboratories. Positive controls for ER $\beta$ IgY are mammary gland and ovary. Positive controls for cx are cell lines expressing ER $\beta$ cx. Negative controls: for each antibody, the antigens were coupled to sepharose beads and shaken with the antibody for $20 \mathrm{~min}$ in the cold. The beads were removed and the supernatant used in immunohistochemistry.

For our study human breast tissue was obtained for a positive control. Secondary antibodies were applied, after which the slides were incubated with avidin biotin complex (ABC; Vector Laboratories, Burlingame, CA, USA) and colored with 3, 3'-diaminobenzidine tetrahydrochloride substrate (DAKO, 
Copenhagen, Denmark). The sections were finally counterstained with Mayer's hematoxylin.

Immunohistochemical evaluation was performed according to the recommendation of Wang et al. [16] by two investigators (E. C. and C. A. R.) who were blinded to the group categorization (age and sex) of the patients. According to Wang et al. [16] the selection of one field is better than when results are based on the average count of three or five fields, and therefore areas with the highest degree of ER expression were evaluated, both in tumor and nontumor tissue. Specimens with $50 \%$ or more of the cells, in a high-power field, positive for ERs were considered positive.

ERs are mainly found in the nucleus [17], but immunoreactivity in the cytoplasm has also been observed [18]. In our study, sections with positive nuclear immunoreactivity were considered as positive. Cytoplasmic (granular) staining was observed in some samples. In particular, positive cytoplasmatic staining with $\beta \mathrm{cx}$ antibody was specific because it could be quenched when the antibody was preabsorbed with the $\beta \mathrm{cx}$ antigen. Although the significance remains to be determined, the staining was included because ER $\beta c x$ escorts ER $\alpha$ to the proteasome for degradation and its presence in cytoplasmic granules may indicate increases in the degradation of $\mathrm{ER} \alpha$ [19]. In addition, we examined both the gastric cancer tissue and the adjacent nontumor tissue, if present in the section.

\section{Statistical analysis}

Fisher's exact test was used to compare the frequency distributions of the three estrogen receptors between the three patient groups. Logistic regression was utilized to estimate relative risks, expressed as odds ratios (ORs) with 95\% confidence intervals (CIs). All statistical analyses were performed with STATA version 9.2 (Stata, College Station, TX, USA). All reported probabilities ( $P$ values) were two-sided, and those less than 0.05 were considered statistically significant.

\section{Ethics}

The regional ethics committee at Karolinska Institutet in Stockholm, Sweden, approved the study.

\section{Results}

\section{Histological type of gastric adenocarcinoma}

Table 1 shows the distribution of the histological types of gastric adenocarcinoma in the three study groups. The occurrence of the intestinal type of gastric adenocarcinoma was lowest among the "exposed women" $(11 \%)$ and highest among the "unexposed women" $(53 \%)$. Compared to "exposed women" the occurrence of the intestinal type was statistically significantly more than four times and nine times higher among "unexposed men" (OR, 4.7; 95\% CI, 2.2-10.3) and "unexposed women" (OR, 9.1; 95\% CI, 4.3-19.6), respectively.

\section{Occurrence of $\alpha, \beta$, and $\beta c x$ estrogen receptors in adenocarcinoma tissue}

Table 2 shows the occurrence of cases with positive nuclear and non-nuclear ER staining in the intestinal type of gastric adenocarcinoma tissue. The tumors of the "unexposed men" had a higher frequency of ER $\alpha$ positive nuclear staining (40\%) compared to "exposed women" (25\%; see example in Fig. 1A), but the difference was not statistically significant. The frequencies of non-nuclear $\mathrm{ER} \alpha$ and $\mathrm{ER} \beta$ were lower in "unexposed men" than in "exposed women", and the difference regarding ER $\alpha$ was statistically significant $(P=0.035)$. The distribution of both nuclear and non-nuclear ERs was similar in "exposed women" and "unexposed women". Although no cases of nuclear staining of ER $\beta \mathrm{cx}$ were found, a total of four $(9 \%)$ cases showed ER $\beta c x$-positive non-nuclear staining.

Table 1. Distribution of the histological types (according to Laurén classification) of gastric adenocarcinoma in the three groups categorized on the basis of their estrogen exposure

\begin{tabular}{lccrc}
\hline Estrogen exposure group & $\begin{array}{c}\text { Intestinal type, } \\
\text { number (\%) }\end{array}$ & $\begin{array}{c}\text { Diffuse type, } \\
\text { number (\%) }\end{array}$ & $\begin{array}{c}\text { Total number } \\
\text { OR (95\% CI) }\end{array}$ \\
\hline Exposed women & $10(11)$ & $80(89)$ & 90 & $1.0($ Reference) \\
Unexposed men & $35(37)$ & $59(63)$ & 94 & $4.7(2.2-10.3)$ \\
Unexposed women & $56(53)$ & $49(47)$ & 105 & $9.1(4.3-19.6)$ \\
\hline
\end{tabular}

Relative risk is expressed as odds ratios (ORs) with $95 \%$ confidence intervals (CIs)

Exposed women: less than 50 years of age; Unexposed men: less than 50 years of age; Unexposed women: more than 70 years of age 
Table 2. Adenocarcinoma tissue

\begin{tabular}{|c|c|c|c|c|c|c|c|}
\hline \multirow[b]{2}{*}{$\begin{array}{l}\text { Estrogen exposure } \\
\text { group }\end{array}$} & \multirow[b]{2}{*}{$\begin{array}{c}\text { Total } \\
\text { number }\end{array}$} & \multicolumn{3}{|c|}{ Nuclear staining } & \multicolumn{3}{|c|}{ Non-nuclear staining } \\
\hline & & $\begin{array}{c}\text { ER } \alpha+ \\
\text { number }(\%) \\
P \text { value }\end{array}$ & $\begin{array}{c}\text { ER } \beta+, \\
\text { number }(\%) \\
P \text { value }\end{array}$ & $\begin{array}{c}\mathrm{ER} \beta \mathrm{cx}+ \\
\text { number }(\%) \\
P \text { value }\end{array}$ & $\begin{array}{c}\text { ER } \alpha+ \\
\text { number }(\%) \\
P \text { value }\end{array}$ & $\begin{array}{c}\text { ER } \beta+, \\
\text { number }(\%) \\
P \text { value }\end{array}$ & $\begin{array}{c}\text { ER } \beta c x+, \\
\text { number }(\%) \\
P \text { value }\end{array}$ \\
\hline \multirow[t]{2}{*}{ Exposed women } & 8 & $2(25)$ & $0(0)$ & $0(0)$ & $4(50)$ & $1(13)$ & $0(0)$ \\
\hline & & Reference & Reference & Reference & Reference & Reference & Reference \\
\hline \multirow[t]{2}{*}{ Unexposed men } & 15 & $6(40)$ & $1(7)$ & $0(0)$ & $1(7)$ & $1(7)$ & $3(20)$ \\
\hline & & 0.476 & - & - & 0.035 & 0.641 & - \\
\hline \multirow[t]{2}{*}{ Unexposed women } & 22 & $5(23)$ & $0(0)$ & $0(0)$ & $11(50)$ & $3(14)$ & $1(5)$ \\
\hline & & 0.896 & - & - & 1 & 0.935 & - \\
\hline Total & 45 & $13(29)$ & $1(2)$ & $0(0)$ & $16(36)$ & $5(11)$ & $4(9)$ \\
\hline
\end{tabular}

Cases of intestinal gastric adenocarcinoma investigated immunohistochemically with regard to the presence of estrogen receptors (ER) $\alpha, \beta$, and $\beta \mathrm{cx}$. Exposed women: less than 50 years of age; unexposed men: less than 50 years of age; unexposed women: more than 70 years of age
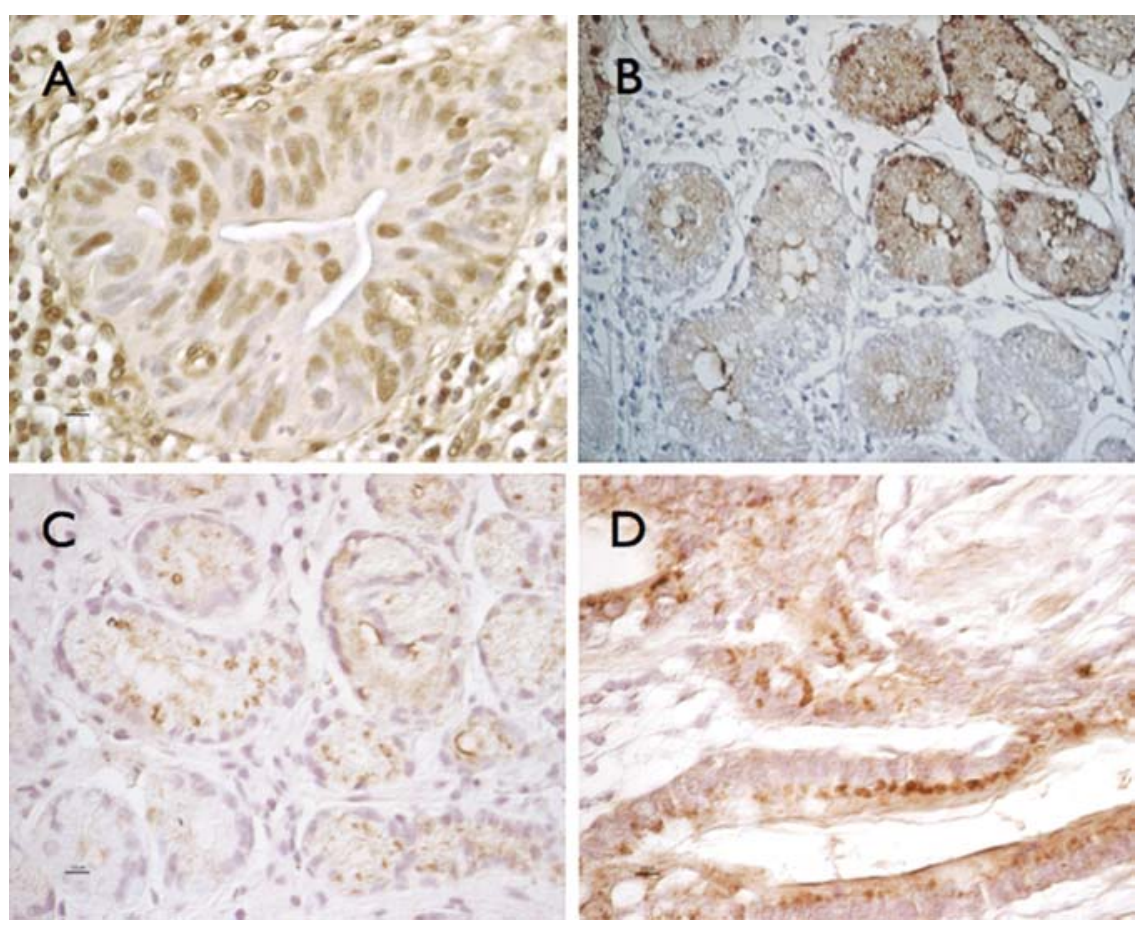

Fig. 1. A Gastric adenocarcinoma of the intestinal type expressing nuclear estrogen receptor $\alpha$, in an estrogen-exposed woman. ER $\alpha, \times 60$. B Pyloric glands adjacent to intestinal gastric adenocarcinoma (not shown), expressing nuclear estrogen receptor $\beta$, in a woman not exposed to estrogen. ER $\beta, \times 40$. C Pyloric glands adjacent to intestinal gastric adenocarcinoma (not shown), expressing estrogen receptor $\beta \mathrm{cx}$ in supranuclear granules, in a woman not exposed to estrogen. ER $\beta c x, \times 40$. D Nontumor glands adjacent to intestinal gastric adenocarcinoma (not shown) expressing estrogen receptor $\beta c x$ in supranuclear granules, in a man not exposed to estrogen. ER $\beta c x, \times 40$

\section{Occurrence of $\alpha, \beta$, and $\beta c x$ estrogen receptors in} nontumor gastric mucosa

Table 3 shows the number of cases with positive nuclear and non-nuclear ER staining in the gastric mucosa adjacent to the gastric tumor among patients with intestinal gastric adenocarcinoma (see examples in Fig. 1B-D). The results were similar to those found for tumor tissue, except for a lower occurrence of ER $\beta$ among unexposed women (Table 3 ). The occurrence of positive nonnuclear ERßcx staining (see examples in Fig. 1C, D) seemed higher in the nontumor tissue. No statistically significant differences were found between the comparison groups.

\section{Comparison of estrogen receptors in the adenocarcinoma and nontumor gastric mucosa}

In all three groups of patients, the percentage of ER $\alpha$ positive cells was higher in the adenocarcinoma tissue than in the adjacent tissue. The opposite trend was noted for ER $\beta$ and $\beta c x$; that is, positive $\beta$ and $\beta c x$ receptors were less frequent (or nonexistent) in the gastric adenocarcinoma tissue than in nontumor tissue.

\section{Discussion}

This study indicated that women exposed to high levels of endogenous estrogen are at lower risk of developing 
Table 3. Nontumor tissue

\begin{tabular}{|c|c|c|c|c|c|c|c|}
\hline \multirow[b]{2}{*}{$\begin{array}{l}\text { Estrogen } \\
\text { exposure group }\end{array}$} & \multirow[b]{2}{*}{ Total number } & \multicolumn{3}{|c|}{ Nuclear staining } & \multicolumn{3}{|c|}{ Non-nuclear staining } \\
\hline & & $\begin{array}{c}\mathrm{ER} \alpha+ \\
\text { number }(\%) \\
P \text { value }\end{array}$ & $\begin{array}{c}\text { ER } \beta+, \\
\text { number }(\%) \\
P \text { value }\end{array}$ & $\begin{array}{c}\text { ER } \beta c x+ \\
\text { number }(\%) \\
P \text { value }\end{array}$ & $\begin{array}{c}\mathrm{ER} \alpha+ \\
\text { number }(\%) \\
P \text { value }\end{array}$ & $\begin{array}{c}\text { ER } \beta+ \\
\text { number }(\%) \\
P \text { value }\end{array}$ & $\begin{array}{c}\text { ER } \beta \mathrm{cx}+ \\
\text { number }(\%) \\
P \text { value }\end{array}$ \\
\hline \multirow[t]{2}{*}{ Exposed women } & \multirow{2}{*}{$\begin{array}{l}7 \text { (6 stained for } \beta \\
\text { and } \beta c x)\end{array}$} & $1(14)$ & $0(0)$ & $0(0)$ & $3(43)$ & $3(50)$ & $2(33)$ \\
\hline & & Reference & Reference & Reference & Reference & Reference & Reference \\
\hline \multirow[t]{2}{*}{ Unexposed men } & \multirow[t]{2}{*}{8} & $3(38)$ & $1(13)$ & $1(13)$ & $0(0)$ & $5(63)$ & $4(50)$ \\
\hline & & 0.326 & - & - & 1 & 0.641 & 0.535 \\
\hline \multirow{2}{*}{$\begin{array}{l}\text { Unexposed } \\
\text { women }\end{array}$} & \multirow[t]{2}{*}{18} & $2(11)$ & $3(17)$ & $0(0)$ & $5(28)$ & $3(17)$ & $5(28)$ \\
\hline & & 0.827 & - & - & 0.472 & 0.119 & 0.796 \\
\hline Total & 33 & $6(18)$ & $4(13)$ & $1(3)$ & $8(24)$ & $11(34)$ & $11(34)$ \\
\hline
\end{tabular}

Cases of intestinal gastric adenocarcinoma investigated immunohistochemically with regard to the presence of estrogen receptors (ER) $\alpha$, $\beta$, and $\beta c x$ in the nontumor gastric mucosa (adjacent to the gastric tumor). Exposed women: less than 50 years of age; unexposed men: less than 50 years of age; unexposed women: more than 70 years of age

the intestinal type of gastric adenocarcinoma, compared to less exposed women or men. No substantial differences in the presence of $\mathrm{ER} \alpha, \beta$, or $\beta \mathrm{cx}$ were found between the three comparison groups with the intestinal type of gastric adenocarcinoma, either in the tumor or in the adjacent tissue. For the first time, ER $\beta c x$ was identified in gastric tissue.

Some methodological aspects of this study deserve consideration. Selection bias was counteracted by the population-based design, all patients being identified from the virtually complete Swedish Cancer Register [12]. The high participation rate regarding the collected tumor material also diminished the risk of selection bias. Tumor misclassification was reduced by our review, in which the gastric adenocarcinoma diagnosis was verified in all study participants. The histological evaluation, the immunohistochemical laboratory work, and the subsequent assessment regarding the presence of ERs were all conducted blindly with regard to the estrogen exposure status of each patient, decreasing the risk of systematic bias. A disadvantage of the study is the small number of intestinal-type gastric adenocarcinoma cases in the ER analyses. Hence, our results regarding the differences in the presence of ERs between the comparison groups must be interpreted with caution. Moreover, the lack of information regarding risk factors for gastric adenocarcinoma prohibited adjustment for potential confounding factors. Other studies have shown, however, that the distribution of the intestinal and diffuse types of gastric adenocarcinoma is not affected by Helicobacter pylori infection [20,21], tobacco use [22], intake of alcoholic beverages [22], intake of fruits or vegetables [23], or occupational exposure [24], and these factors should not therefore act as confounders in our analyses of histological type. A high socioeconomic status may, however, lower the risk of developing the intestinal type of adenocarcinoma [25]. The relation between these risk factors and ER status has never been evaluated and it is therefore not possible to know whether they would have affected our results.

Some epidemiological studies indicate that exogenous estrogen has a protective effect on the risk of gastric adenocarcinoma development. In a Swedish cohort study of prostate cancer patients, the risk of gastric adenocarcinoma was lower among those who were treated with estrogen [5]. In a cohort of postmenopausal women in the United Kingdom, a decreased risk of gastric adenocarcinoma was found among users of hormone replacement therapy [4], which is in line with an Italian study [26]. In a cohort study of breast cancer patients in Sweden, women who had received antiestrogen treatment with tamoxifen had an increased risk of subsequently developing gastric adenocarcinoma compared to patients without such treatment [3].

With regard to endogenous estrogen exposure, a global pattern with a male predominance unique for gastric adenocarcinoma of the intestinal type and with a 10- to 15-year delay in its incidence in women has been reported [2]. A Canadian study offers further support to the hypothesis that high endogenous estrogen exposure reduces the risk of gastric cancer, in particular of the intestinal type [6]. Moreover, in a recently published Chinese prospective study in which a large cohort of women was followed up, the results suggested that female hormones play a protective role against the risk of gastric cancer [27]. Others too have found similar associations; for instance, a longer fertility life has been reported to decrease the risk of gastric cancer [28-31], although not all agree with this finding [32]. Our results regarding the differences in the distribution of the two histological types of gastric adenocarcinoma in the three patient groups gain support from some previous studies [33-35]. Thus, the hypothesis that endogenous estrogen exposure decreases the risk of the intestinal type of gastric adenocarcinoma might be true, but the mechanisms underlying this effect are unclear. 
We hypothesized that the protective effect of estrogen on gastric intestinal adenocarcinoma development is mediated by ERs, a concept that has not, to our knowledge, been tested previously. The reported decrease in the risk of colorectal cancer among women using postmenopausal hormone therapy [36-38], might, however, be mediated by ER $\beta$ [39], the predominant ER identified in colonic epithelium [39, 40]. Nevertheless, our results do not provide any strong evidence that ERs are mediators of the possible protective effect of endogenous estrogen exposure. In a previous study of ERs in gastric cancer, a decreased ER-positive rate with age was found in women [41], but all types of gastric cancer were included in the analysis. In another study, no sex differences were observed with regard to ER expression, but the frequency of ER-positive cancers was higher in postmenopausal than in premenopausal women [42]. The number of cases was small, however, and no distinction was made between the two histological types of gastric adenocarcinoma. Thus, the potential role of ERs in mediating the low occurrence of gastric adenocarcinoma of the intestinal type remains uncertain.

We did, however, find differences in the occurrence of ER-positivity between tumor and nontumor adjacent gastric tissue in all three patient groups. The decreased expression of ER $\beta$ and $\beta c x$ in the gastric adenocarcinoma tissue compared to the nontumor gastric mucosa adjacent to the tumor is in accordance with reports of decreased expression of ER $\beta$ in breast [43] and prostate [44] cancer cells, as well as in gastric adenocarcinoma [45]. In addition, we found increased expression of ER $\alpha$ in gastric adenocarcinoma tissue compared to nontumor tissue, which is in line with the results of a study of breast cancer [43]. Interestingly, we also report, for the first time, the existence of ER $\beta c x$ in the stomach. ER $\beta c x$ is known to be expressed in the thymus, ovaries, testis, and prostate [11, 46], and in the breast [47]. ER $\beta \mathrm{cx}$ does not bind estrogen; instead, it inhibits ER $\alpha$ from binding DNA, while it does not influence ER $\beta$ [46]. The significance of the presence of ER $\beta c x$ in gastric adenocarcinoma remains to be further investigated.

In this study we combined population-based data collection with experimental analyses to try to elucidate in greater detail the possible sex hormonal involvement in the male predominance in the incidence of gastric adenocarcinoma. Clearly, more studies are needed to establish the roles of endogenous and exogenous estrogen exposure and ERs. Gastric cancer remains the second most common cause of cancer death worldwide [1], emphasizing the importance of understanding its etiology. Speculatively, future research that can establish the potential role of estrogen and ERs in relation to gastric adenocarcinoma might open the way for adjuvant or preventive strategies in the treatment of this cancer, e.g., through the action of more selective ER modulators, and probably of specific ER $\beta$ agonists, because these receptors promote epithelial differentiation [39].

In conclusion, this epidemiological and experimental study provided evidence in favor of the hypothesis that women currently exposed to endogenous estrogen are at decreased risk of developing the intestinal type of gastric adenocarcinoma. Because no material differences in the distribution of ERs in the intestinal type of gastric adenocarcinoma with regard to endogenous estrogen exposure status were found, the role of ERs in explaining this sex difference remains uncertain. Nevertheless, our data indicate that the expression of ERs is altered in gastric adenocarcinoma compared to that in nontumor gastric mucosa, and for the first time the existence of ER $\beta c x$ in the stomach is reported.

Acknowledgments Financial support was provided by the Swedish Research Council and Swedish Cancer Society.

\section{References}

1. Parkin DM, Bray F, Ferlay J, Pisani P. Global cancer statistics, 2002. CA Cancer J Clin 2005;55:74-108.

2. Sipponen P, Correa P. Delayed rise in incidence of gastric cancer in females results in unique sex ratio $(\mathrm{M} / \mathrm{F})$ pattern: etiologic hypothesis. Gastric Cancer 2002;5:213-9.

3. Chandanos E, Lindblad M, Jia C, Rubio CA, Ye W, Lagergren J. Tamoxifen exposure and risk of oesophageal and gastric adenocarcinoma: a population-based cohort study of breast cancer patients in Sweden. Br J Cancer 2006;95:118-22.

4. Lindblad M, Garcia Rodriguez LA, Chandanos E, Lagergren J. Hormone replacement therapy and risks of oesophageal and gastric adenocarcinomas. Br J Cancer 2006;94:136-41.

5. Lindblad M, Ye W, Rubio C, Lagergren J. Estrogen and risk of gastric cancer: a protective effect in a nationwide cohort study of patients with prostate cancer in Sweden. Cancer Epidemiol Biomarkers Prev 2004;13:2203-7.

6. Frise S, Kreiger N, Gallinger S, Tomlinson G, Cotterchio M. Menstrual and reproductive risk factors and risk for gastric adenocarcinoma in women: findings from the Canadian National Enhanced Cancer Surveillance System. Ann Epidemiol 2006;16: 908-16.

7. Greene GL, Gilna P, Waterfield M, Baker A, Hort Y, Shine J. Sequence and expression of human estrogen receptor complementary DNA. Science 1986;231:1150-4.

8. Kuiper GG, Enmark E, Pelto-Huikko M, Nilsson S, Gustafsson JA. Cloning of a novel receptor expressed in rat prostate and ovary. Proc Natl Acad Sci U S A 1996;93:5925-30.

9. Matsuyama S, Ohkura Y, Eguchi H, Kobayashi Y, Akagi K, Uchida $\mathrm{K}$, et al. Estrogen receptor beta is expressed in human stomach adenocarcinoma. J Cancer Res Clin Oncol 2002;128: 319-24.

10. Tokunaga A, Kojima N, Andoh T, Matsukura N, Yoshiyasu M, Tanaka N, et al. Hormone receptors in gastric cancer. Eur J Cancer Clin Oncol 1983;19:687-9.

11. Moore JT, McKee DD, Slentz-Kesler K, Moore LB, Jones SA, Horne EL, et al. Cloning and characterization of human estrogen receptor beta isoforms. Biochem Biophys Res Commun 1998; 247:75-8. 
12. Ekstrom AM, Signorello LB, Hansson LE, Bergstrom R, Lindgren A, Nyren O. Evaluating gastric cancer misclassification: a potential explanation for the rise in cardia cancer incidence. $\mathrm{J}$ Natl Cancer Inst 1999;91:786-90.

13. Laurén P. The two histological main types of gastric carcinoma: diffuse and so-called intestinal-type carcinoma. An attempt at a histo-clinical classification. Acta Pathol Microbiol Scand 1965; 64:31-49.

14. Ming SC. Gastric carcinoma. A pathobiological classification. Cancer 1977;39:2475-85.

15. Palmieri C, Lam EW, Mansi J, MacDonald C, Shousha S, Madden $\mathrm{P}$, et al. The expression of ER beta cx in human breast cancer and the relationship to endocrine therapy and survival. Clin Cancer Res 2004;10:2421-8.

16. Wang HH, Mangano MM, Antonioli DA. Evaluation of Tlymphocytes in esophageal mucosal biopsies. Mod Pathol 1994;7: $55-8$.

17. Heldring N, Pike A, Andersson S, Matthews J, Cheng G, Hartman J, et al. Estrogen receptors: how do they signal and what are their targets. Physiol Rev 2007;87:905-31.

18. Matsui M, Kojima O, Uehara Y, Takahashi T. Characterization of estrogen receptor in human gastric cancer. Cancer 1991;68: $305-8$.

19. Zhao C, Matthews J, Tujague M, Wan J, Strom A, Toresson G, et al. Estrogen receptor beta2 negatively regulates the transactivation of estrogen receptor alpha in human breast cancer cells. Cancer Res 2007:67:3955-62.

20. Hansson LR, Engstrand L, Nyren O, Lindgren A. Prevalence of Helicobacter pylori infection in subtypes of gastric cancer. Gastroenterology 1995;109:885-8.

21. Wang C, Yuan Y, Hunt RH. The association between Helicobacter pylori infection and early gastric cancer: a meta-analysis. Am J Gastroenterol 2007;102:1789-98.

22. Ye W, Ekstrom AM, Hansson LE, Bergstrom R, Nyren O. Tobacco, alcohol and the risk of gastric cancer by sub-site and histologic type. Int J Cancer 1999;83:223-9.

23. Lunet N, Valbuena C, Vieira AL, Lopes C, Lopes C, David L, et al. Fruit and vegetable consumption and gastric cancer by location and histological type: case-control and meta-analysis. Eur J Cancer Prev 2007;16:312-27.

24. Ekstrom AM, Eriksson M, Hansson LE, Lindgren A, Signorello $\mathrm{LB}$, Nyren $\mathrm{O}$, et al. Occupational exposures and risk of gastric cancer in a population-based case-control study. Cancer Res 1999;59:5932-7.

25. Nagel G, Linseisen J, Boshuizen HC, Pera G, Del Giudice G, Westert GP, et al. Socioeconomic position and the risk of gastric and oesophageal cancer in the European Prospective Investigation into Cancer and Nutrition (EPIC-EURGAST). Int J Epidemiol 2007;36:66-76.

26. Fernandez E, Gallus S, Bosetti C, Franceschi S, Negri E, La Vecchia C. Hormone replacement therapy and cancer risk: a systematic analysis from a network of case-control studies. Int $\mathrm{J}$ Cancer 2003;105:408-12.

27. Freedman ND, Chow WH, Gao YT, Shu XO, Ji BT, Yang G, et al. Menstrual and reproductive factors and gastric cancer risk in a large prospective study of women. Gut 2007;56:1671-7.

28. Inoue M, Ito LS, Tajima K, Yamamura Y, Kodera Y, Takezaki $\mathrm{T}$, et al. Height, weight, menstrual and reproductive factors and risk of gastric cancer among Japanese postmenopausal women: analysis by subsite and histologic subtype. Int J Cancer 2002;97: 833-8.

29. Kaneko S, Tamakoshi A, Ohno Y, Mizoue T, Yoshimura T. Menstrual and reproductive factors and the mortality risk of gastric cancer in Japanese menopausal females. Cancer Causes Control $2003 \cdot 14: 53-9$
30. La Vecchia C, D’Avanzo B, Franceschi S, Negri E, Parazzini F, Decarli A. Menstrual and reproductive factors and gastric-cancer risk in women. Int J Cancer 1994;59:761-4.

31. Palli D, Cipriani F, Decarli A, Galli M, Saieva C, Fraumeni JF Jr, et al. Reproductive history and gastric cancer among postmenopausal women. Int J Cancer 1994;56:812-5.

32. Heuch I, Kvale G. Menstrual and reproductive factors and risk of gastric cancer: a Norwegian cohort study. Cancer Causes Control 2000;11:869-74.

33. Lauren PA, Nevalainen TJ. Epidemiology of intestinal and diffuse types of gastric carcinoma. A time-trend study in Finland with comparison between studies from high- and low-risk areas. Cancer 1993;71:2926-33.

34. Sipponen P, Marshall BJ. Gastritis and gastric cancer. Western countries. Gastroenterol Clin North Am 2000;29:579-92, v-vi.

35. Stemmermann GN, Brown C. A survival study of intestinal and diffuse types of gastric carcinoma. Cancer 1974;33:1190-5.

36. Chlebowski RT, Wactawski-Wende J, Ritenbaugh C, Hubbell FA, Ascensao J, Rodabough RJ, et al. Estrogen plus progestin and colorectal cancer in postmenopausal women. N Engl J Med 2004;350:991-1004.

37. Grodstein F, Newcomb PA, Stampfer MJ. Postmenopausal hormone therapy and the risk of colorectal cancer: a review and meta-analysis. Am J Med 1999;106:574-82.

38. Rossouw JE, Anderson GL, Prentice RL, LaCroix AZ, Kooperberg C, Stefanick ML, et al. Risks and benefits of estrogen plus progestin in healthy postmenopausal women: principal results From the Women's Health Initiative randomized controlled trial. JAMA 2002;288:321-33.

39. Wada-Hiraike O, Imamov O, Hiraike H, Hultenby K, Schwend $\mathrm{T}$, Omoto Y, et al. Role of estrogen receptor beta in colonic epithelium. Proc Natl Acad Sci U S A 2006:103:2959-64.

40. Konstantinopoulos PA, Kominea A, Vandoros G, Sykiotis GP, Andricopoulos P, Varakis I, et al. Oestrogen receptor beta (ERbeta) is abundantly expressed in normal colonic mucosa, but declines in colon adenocarcinoma paralleling the tumour's dedifferentiation. Eur J Cancer 2003;39:1251-8.

41. Kojima O, Takahashi T, Kawakami S, Uehara Y, Matsui M. Localization of estrogen receptors in gastric cancer using immunohistochemical staining of monoclonal antibody. Cancer 1991;67: 2401-6.

42. Sica V, Nola E, Contieri E, Bova R, Masucci MT, Medici N, et al. Estradiol and progesterone receptors in malignant gastrointestinal tumors. Cancer Res 1984;44:4670-4.

43. Roger P, Sahla ME, Makela S, Gustafsson JA, Baldet P, Rochefort H. Decreased expression of estrogen receptor beta protein in proliferative preinvasive mammary tumors. Cancer Res 2001;61:2537-41.

44. Horvath LG, Henshall SM, Lee CS, Head DR, Quinn DI, Makela $\mathrm{S}$, et al. Frequent loss of estrogen receptor-beta expression in prostate cancer. Cancer Res 2001;61:5331-5.

45. Wang M, Pan JY, Song GR, Chen HB, An LJ, Qu SX. Altered expression of estrogen receptor alpha and beta in advanced gastric adenocarcinoma: correlation with prothymosin alpha and clinicopathological parameters. Eur J Surg Oncol 2007;33: 195-201.

46. Ogawa S, Inoue S, Watanabe T, Orimo A, Hosoi T, Ouchi Y, et al. Molecular cloning and characterization of human estrogen receptor betacx: a potential inhibitor of estrogen action in humans. Nucleic Acids Res 1998;26:3505-12.

47. Esslimani-Sahla M, Simony-Lafontaine J, Kramar A, Lavaill R, Mollevi C, Warner M, et al. Estrogen receptor beta (ER beta) level but not its ER beta cx variant helps to predict tamoxifen resistance in breast cancer. Clin Cancer Res 2004;10:576976. 